\title{
Caldicellulosiruptor kronotskyensis sp. nov. and Caldicellulosiruptor hydrothermalis sp. nov., two extremely thermophilic, cellulolytic, anaerobic bacteria from Kamchatka thermal springs
}

Correspondence

Margarita L. Miroshnichenko alfamirr@mail.ru

\author{
Margarita L. Miroshnichenko, ${ }^{1}$ Ilya V. Kublanov, ${ }^{1}$ Nadezhda A. Kostrikina, ${ }^{1}$ \\ Tatyana P. Tourova, ${ }^{1}$ Tatyana V. Kolganova, ${ }^{2}$ Nils-Kåre Birkeland $^{3}$ \\ and Elizaveta A. Bonch-Osmolovskaya ${ }^{1}$
${ }^{1}$ Winogradsky Institute of Microbiology, Russian Academy of Sciences, Prospect 60 Letiya Oktyabrya 7/2, 117312 Moscow, Russia 117312 Moscow, Russia
${ }^{3}$ Department of Biology and Center of Geobiology, University of Bergen, PO Box 7800, N-5020 \\ ${ }^{2}$ Bioengeneering Center, Russian Academy of Sciences, Prospect 60 Letiya Oktyabrya 7/1, \\ Bergen, Norway
}

\begin{abstract}
Five novel strains $\left(2002^{\top}, 2902,2006,108^{\top}\right.$ and 117$)$ of cellulose-degrading, anaerobic, thermophilic bacteria were isolated from terrestrial hot springs of Kamchatka (Far East, Russia). Strains $2002^{\top}$ and $108^{\top}$ were non-spore-forming bacteria with a Gram-positive type cell wall and peritrichous flagella. Optimum growth of strains $2002^{\top}$ and $108^{\top}$ occurred at $\mathrm{pH} 7.0$ and at temperatures of 70 and $65{ }^{\circ} \mathrm{C}$, respectively. The $\mathrm{G}+\mathrm{C}$ contents of the DNA of strains $2002^{\top}$ and $108^{\top}$ were 35.1 and 36.4 mol\%, respectively. Comparative $16 \mathrm{~S}$ rRNA gene sequence analysis revealed that the isolates belonged to the genus Caldicellulosiruptor. However, DNA-DNA hybridization experiments indicated that the levels of relatedness between strains $2002^{\top}$ and $108^{\top}$ and those of recognized members of the genus Caldicellulosiruptor ranged between 32 and $54 \%$. Based on both phenotypic and genomic differences, strains $2002^{\top}$ and $108^{\top}$ are considered to represent two novel species of the genus Caldicellulosiruptor. The names proposed for these organisms are Caldicellulosiruptor kronotskyensis sp. nov. (type strain $2002^{\top}=\mathrm{DSM} 18902^{\top}=$ VKM B-2412 $2^{\top}$ ) and Caldicellulosiruptor hydrothermalis sp. nov. (type strain $108^{\top}=$ DSM $18901^{\top}=$ VKM B-2411 ${ }^{\top}$ ).
\end{abstract}

Cellulolytic capability is widely distributed across the domain Bacteria and is displayed by a physiologically and phylogenetically diverse group of micro-organisms that differ in growth temperature, salt tolerance and relation to oxygen. Extremely thermophilic cellulose-degrading microorganisms are of particular fundamental and biotechnological interest owing to the presence of highly thermostable enzymes. The group of thermophilic cellulolytic prokaryotes includes two aerobic species, Rhodothermus marinus and Acidothermus cellulolyticus, and numerous anaerobes of the genera Caldicellulosiruptor, Clostridium, Spirochaeta, Fervidobacterium and Thermotoga (reviewed by Bergquist et al., 1999). At the time of writing, the genus Caldicellulosiruptor comprised five species with validly published names: Caldicellulosiruptor saccharolyticus

The GenBank/EMBL/DDBJ accession numbers for the $16 \mathrm{~S}$ rRNA gene sequences of strains $2002^{\top}$ and $108^{\top}$ are EF100909 and EF100908, respectively.
(Rainey et al., 1994), Caldicellulosiruptor lactoaceticus (Mladenovska et al., 1995), Caldicellulosiruptor owensensis (Huang et al., 1998), Caldicellulosiruptor kristjanssonii (Bredholt et al., 1999) and Caldicellulosiruptor acetigenus (Onyenwoke et al., 2006). All members of the genus Caldicellulosiruptor are extremely thermophilic, cellulolytic, non-spore-forming anaerobes with Gram-positive type cell wall, and are capable of fermenting a wide spectrum of carbohydrates. These bacteria have been isolated mostly from neutral or slightly alkaline geothermal springs in New Zealand, Iceland and California.

The hot springs of Kamchatka have also provided the source of isolation of anaerobic, thermophilic, cellulolytic bacteria. 'Dictyoglomus turgidus' was isolated from Uzon caldera (Svetlichnii \& Svetlichnaya, 1988) and 'Anaerocellum thermophilum' was isolated from the Valley of Geysers (Svetlichnii et al., 1990). 16S rRNA gene sequence analysis subsequently placed the latter organism 
within the genus Caldicellulosiruptor (Mladenovska et al., 1995). In the present study, we describe two novel thermophilic, cellulose-degrading, anaerobic bacteria isolated from hot springs of Kamchatka (Russia).

Five strains of cellulose-degrading micro-organisms were isolated from samples collected from thermal springs of the Kamchatka peninsula, at Geyser Valley (Kronotsky National Park), Moutnovsky Volcano and the Pauzhetka group of thermal springs. The sampling sites, with temperatures varying from 55 to $65{ }^{\circ} \mathrm{C}$ and $\mathrm{pH} 4.5-8.0$, were rich in dead plant material. Enrichment cultures were made by inoculating $10 \%(\mathrm{w} / \mathrm{v})$ of 12 samples into Hungate tubes with anaerobically prepared sterile Pfennig medium (Pfennig, 1965), supplemented with microcrystalline cellulose $\left(10 \mathrm{~g} \mathrm{l}^{-1}\right)$, yeast extract $\left(0.2 \mathrm{~g} \mathrm{l}^{-1}\right.$; Difco), resazurin $\left(1 \mathrm{mg} \mathrm{l}^{-1}\right)$, trace element solution $\left(1 \mathrm{ml} \mathrm{l}^{-1}\right.$; Pfennig \& Lippert, 1966) and vitamin solution $\left(1 \mathrm{ml} \mathrm{l}^{-1}\right.$; Wolin et al., 1963). $\mathrm{N}_{2}$ was used as gas phase. Within 34 days of incubation at $70{ }^{\circ} \mathrm{C}$, turbidity and gas bubbles caused by intensive microbial growth were observed in five tubes. Positive enrichment cultures were subcultured three times and then serially diluted in agar shake tubes, containing the same medium but without cellulose, solidified with $2 \%$ agar (Difco) and supplemented with cellobiose $\left(1 \mathrm{~g} \mathrm{l}^{-1}\right.$; Sigma). Agar shake tubes were incubated at $60{ }^{\circ} \mathrm{C}$ for 1 week. Single colonies from the highest positive dilutions were picked and inoculated into liquid medium containing microcrystalline cellulose. Colonies were $1-1.2 \mathrm{~mm}$ in diameter, spherical and milk or slightly creamy white in colour. The purification procedure was repeated twice. Finally, five pure cultures were obtained and these were designated strains $108^{\mathrm{T}}$ and 117 (both from Pauzhetka), 2902 (from Moutnovsky Volcano), and 2006 and $2002^{\mathrm{T}}$ (both from Geyser Valley).

For amplification and sequencing of $16 \mathrm{~S}$ rRNA genes, DNA was obtained by standard phenol/chloroform extraction. The 16S rRNA genes were selectively amplified by using primers 5'-AGAGTTGATCCTGGCTCAG-3' (forward) and $5^{\prime}$-TACGGTTACCTTGTTACGACTT-3' (reverse) and the PCR products were purified by using a Wizard PCR-Prep kit (Promega) according to the manufacturer's instructions. Sequencing was performed by using a BigDye Terminator v. 3.1 sequencing reaction kit and the sequencing reactions were run on an ABI 3730 DNA automatic sequencer (Applied Biosystems). Positions that had not been sequenced in one or more reference organisms were omitted from analysis. Pairwise evolutionary distances were computed by using the correction of Jukes \& Cantor (1969). Preliminary phylogenetic analysis of the new sequences was done with the NCBI BLAST server (http://www.ncbi.nlm.nih.gov/BLAST/). Nucleotide sequences were aligned with sequences from GenBank by

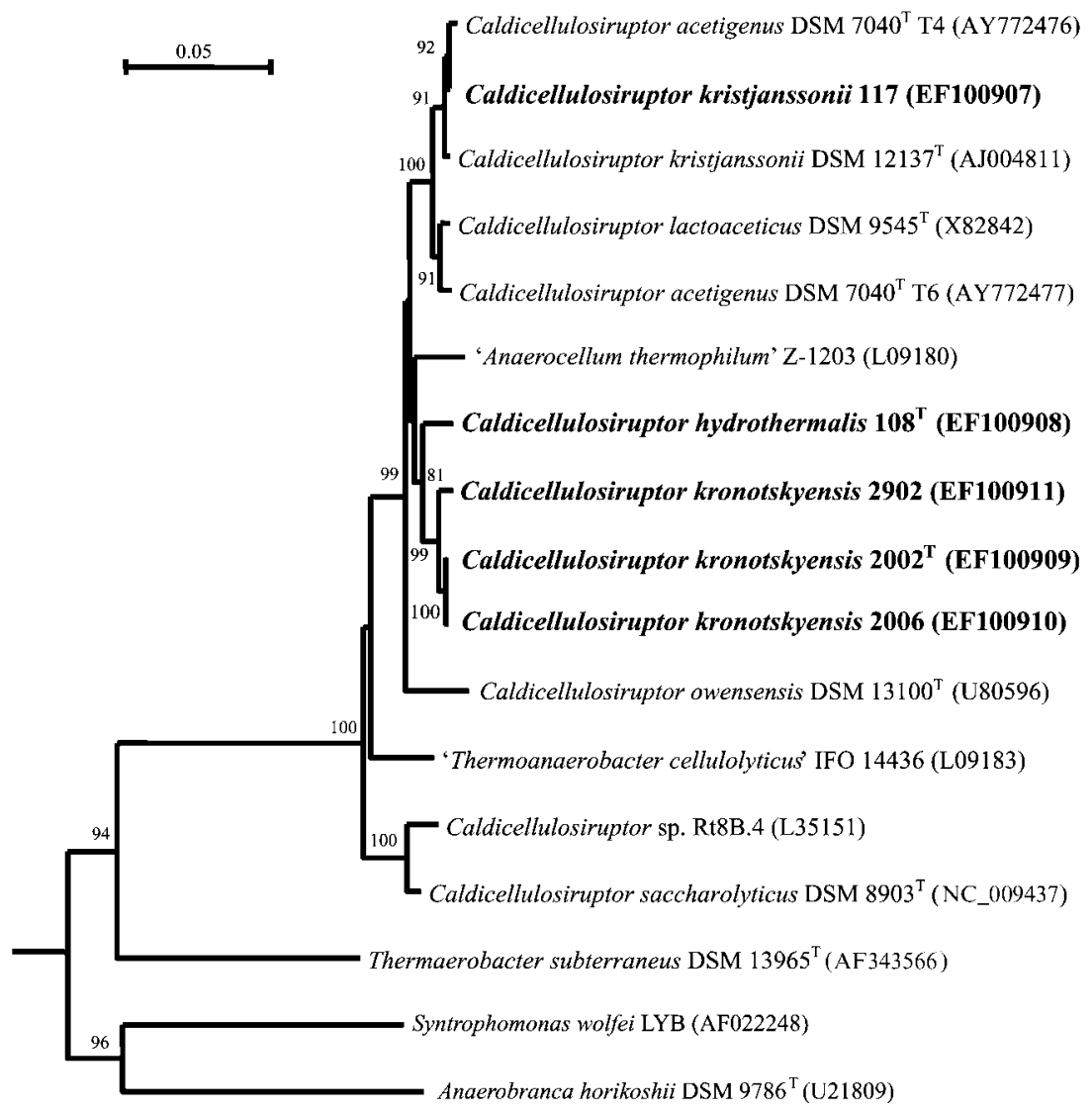

Fig. 1. Neighbour-joining phylogenetic tree based on 16S rRNA gene sequences showing the positions of strains $108^{\top}, 117,2002^{\top}$, 2006 and 2902 among members of the genus Caldicellulosiruptor. Bootstrap values (expressed as percentages of 100 replications) are shown at branch points; values of $>70 \%$ were considered to be significant. Bar, Jukes-Cantor distance (5 nucleotide substitutions per 100 nucleotides). 
using CLUSTAL W. The unrooted phylogenetic tree was constructed according to the neighbour-joining method by using the TREECONW program package (Van de Peer \& De Wachter, 1994).

Almost-complete (nearly $1500 \mathrm{nt}$ ) sequences of the $16 \mathrm{~S}$ rRNA genes of strains $108^{\mathrm{T}}, 117,2902,2006$ and $2002^{\mathrm{T}}$ were determined. In initial analyses, the 16S rRNA gene sequences of these strains were compared with corresponding GenBank sequence data. Preliminary analysis revealed that the new sequences grouped with those of members of the genus Caldicellulosiruptor (Rainey et al., 1994) within the family Syntrophomonadaceae of Grampositive bacteria (Garrity et al., 2001). The phylogenetic tree generated (Fig. 1) showed clearly that the novel strains fell within the radiation of recognized Caldicellulosiruptor species. The $16 \mathrm{~S}$ rRNA gene sequence of strain 117 was almost identical to that of the type strain of Caldicellulosiruptor kristjanssonii (99.5\% similarity) and Caldicellulosiruptor acetigenus (99.7\%). The 16S rRNA gene sequences of strains 2902, 2006 and $2002^{\mathrm{T}}$ were almost identical to each other (99.2-99.9\% similarity) and formed a single separate cluster among recognized Caldicellulosiruptor species, with levels of similarity of $94.8-97.7 \%$ to the type strains of these latter species. The $16 \mathrm{~S}$ rRNA gene sequence of strain $108^{\mathrm{T}}$ was closely related to this cluster, with sequence similarity values of 98.1$98.2 \%$, whereas it showed lower levels of similarity to the type strains of recognized Caldicellulosiruptor species (94.5-97.6\%).

The new isolates were compared with each other and all recognized species of the genus Caldicellulosiruptor based on DNA-DNA hybridization experiments (Miroshnichenko et al., 1994). The following reference strains were used: Caldicellulosiruptor saccharolyticus DSM $8903^{\mathrm{T}}$, Caldicellulosiruptor kristjanssonii DSM $12137^{\mathrm{T}}$, Caldicellulosiruptor lactoaceticus DSM $9545^{\mathrm{T}}$, Caldicellulosiruptor owensensis DSM $13100^{\mathrm{T}}$ and Caldicellulosiruptor acetigenus DSM $7040^{\mathrm{T}}$. The level of DNA-DNA relatedness between strain 117 and Caldicellulosiruptor kristjanssonii DSM $12137^{\mathrm{T}}$ was $83 \%$. Strain 117 was thus considered to represent Caldicellulosiruptor kristjanssonii. The high level of DNADNA relatedness (80-92\%) found between strains 2902, 2006 and $2002^{\mathrm{T}}$ indicated that they were strains of the same species. Levels of DNA-DNA relatedness between strain $2002^{\mathrm{T}}$ and the above reference Caldicellulosiruptor strains were $46 \%$ (with Caldicellulosiruptor lactoaceticus DSM $9545^{\mathrm{T}}$ ) or lower, and between strain $108^{\mathrm{T}}$ and the same reference strains were $54 \%$ (with Caldicellulosiruptor lactoaceticus DSM $9545^{\mathrm{T}}$ ) or lower. By contrast, the level of DNA-DNA relatedness between strains $2002^{\mathrm{T}}$ and $108^{\mathrm{T}}$ $(40 \%)$ clearly revealed a lack of relationship at the species level. Based on these genomic DNA studies, strains $2002^{\mathrm{T}}$ and $108^{\mathrm{T}}$ were chosen for further characterization.

Cells of the new isolates as revealed by transmission electron microscopy (Bonch-Osmolovskaya et al., 1990) were morphologically similar, being short $(3-3.2 \times 0.5-$
$0.7 \mu \mathrm{m})$ straight rods with rounded ends and peritrichous flagella (Fig. 2a). Thin-section analysis revealed Grampositive type cell walls (Fig. 2b). Cells occurred singly, in pairs or in short chains. Spores were not observed.

The results of phenotypic characterization of isolates $2002^{\mathrm{T}}$ and $108^{\mathrm{T}}$ are presented in Table 1. Growth experiments were performed by using the same basal medium as used for enrichment and isolation, but supplemented with maltose $(20 \mathrm{mM})$ as the growth substrate. Other substrates tested were added at concentrations of $20 \mathrm{mM}$ (soluble substrates) or $10 \mathrm{~g} \mathrm{l}^{-1}$ (cellulose, xylan, dextran). Isolates $2002^{\mathrm{T}}$ and $108^{\mathrm{T}}$ grew under strictly anaerobic conditions, but were able to grow well on the anaerobically prepared medium without any reducing agent. The temperature range for growth was between 45 and $82{ }^{\circ} \mathrm{C}$ (optimum at $70{ }^{\circ} \mathrm{C}$ ) for strain $2002^{\mathrm{T}}$ and between 50 and $80{ }^{\circ} \mathrm{C}$ (optimum at $65{ }^{\circ} \mathrm{C}$ ) for strain $108^{\mathrm{T}}$. The two strains grew over the $\mathrm{pH}$ range 6.0-8.0 with optimum growth at $\mathrm{pH} 7.0$. The generation time for strains $108^{\mathrm{T}}$ and $2002^{\mathrm{T}}$ growing on maltose under optimal conditions was 2 and $2.5 \mathrm{~h}$, respectively. Substrates utilized by strain $2002^{\mathrm{T}}$ included cellulose, carboxymethylcellulose (CM-cellulose), filter paper, starch, dextran, xylan, pectin, cellobiose, glucose, fructose, galactose, sucrose, maltose, lactose, arabinose, xylose, trehalose, mannitol, yeast extract and peptone.
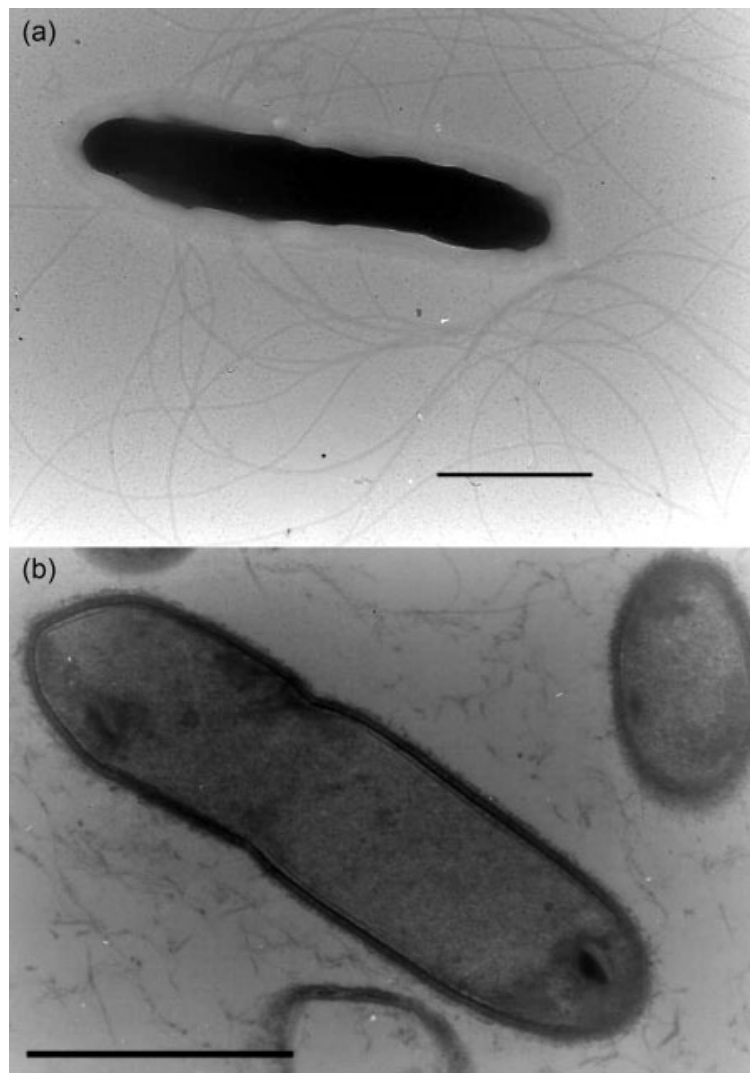

Fig. 2. Electron micrographs of (a) negatively stained and (b) thinsectioned cells of strain $108^{\top}$. Bars, $0.5 \mu \mathrm{m}$. 
Strains 2902 and 2006 shared with strain $2002^{\mathrm{T}}$ the ability to use peptone and trehalose as carbon sources. Strain $108^{\mathrm{T}}$ grew well on cellulose, CM-cellulose, filter paper, starch, dextran, xylan, pectin, cellobiose, glucose, fructose, galactose, sucrose, maltose, lactose, arabinose, xylose, mannitol and yeast extract. Strains $108^{\mathrm{T}}$ and $2002^{\mathrm{T}}$ were unable to grow with pyruvate, chitin, raffinose or ribose.

The main end products of glucose fermentation by strains $2002^{\mathrm{T}}$ and $108^{\mathrm{T}}$ were determined by GLC by using a Stayer chromatograph, UV/VID detector (wavelength $220 \mathrm{~nm}$ ), REZEX ROA $300 \times 7.8-\mathrm{mm}$ column (Phenomenex), maintained at $35{ }^{\circ} \mathrm{C}$, and $0.2 \% \mathrm{H}_{3} \mathrm{PO}_{4}$ solution as a solvent at a flow rate of $0.5 \mathrm{ml} \mathrm{min}{ }^{-1}$. The main end products found were lactate and acetate.

Table 1 details differential characteristics of strains $2002^{\mathrm{T}}$ and $108^{\mathrm{T}}$ as compared with recognized species of the genus Caldicellulosiruptor. Based on DNA-DNA hybridization experiments, strains $2002^{\mathrm{T}}$ and $108^{\mathrm{T}}$ are most closely related to the type strain of Caldicellulosiruptor lactoaceticus (46 and $54 \%$, respectively). However, strains $2002^{\mathrm{T}}$ and $108^{\mathrm{T}}$ could be differentiated from Caldicellulosiruptor lactoaceticus based on a much wider spectrum of utilized substrates (Table 1). At the same time, the low level of DNA-DNA relatedness between strains $2002^{\mathrm{T}}$ and $108^{\mathrm{T}}$ $(40 \%)$ and differences between these two strains in the ability to utilize peptone and trehalose indicate that they represent two different species. We therefore suggest that strains $2002^{\mathrm{T}}$ and $108^{\mathrm{T}}$ represent two novel species of the genus Caldicellulosiruptor, for which the names Caldicellulosiruptor kronotskyensis sp. nov. and Caldicellulosiruptor hydrothermalis sp. nov. are proposed, respectively.

\section{Description of Caldicellulosiruptor kronotskyensis sp. nov.}

Caldicellulosiruptor kronotskyensis (kro.no.t'sky.en.sis. N.L. masc. adj. kronotskyensis pertaining to Kronotsky National Park, Kamchatka, Russia, from where the type strain was isolated).

Cells are short, straight rods $(3-3.2 \times 0.5-0.7 \mu \mathrm{m})$ with flagella. Cell wall is of Gram-positive type. Non-sporeforming. Strictly anaerobic. Temperature range for growth is $45-82{ }^{\circ} \mathrm{C}$, with optimum growth at $70{ }^{\circ} \mathrm{C}$; $\mathrm{pH}$ range for growth is 6.0-8.0, with optimum growth at $\mathrm{pH}$ 7.0.

Table 1. Differential characteristics between strain $108^{\top}$, strain $2002^{\top}$ and members of the genus Caldicellulosiruptor

Taxa: 1, Caldicellulosiruptor saccharolyticus (data from Rainey et al., 1994); 2, Caldicellulosiruptor lactoaceticus (Mladenovska et al., 1995); 3, Caldicellulosiruptor owensensis (Huang et al., 1998); 4, Caldicellulosiruptor kristjanssonii (Bredholt et al., 1999); 5, Caldicellulosiruptor acetigenus (Onyenwoke et al., 2006); 6, strain $2002^{\mathrm{T}}$ (Caldicellulosiruptor kronotskyensis sp. nov.); 7 , strain $108^{\mathrm{T}}$ (Caldicellulosiruptor hydrothermalis sp. nov.). + , Positive; -, negative; NR, not reported.

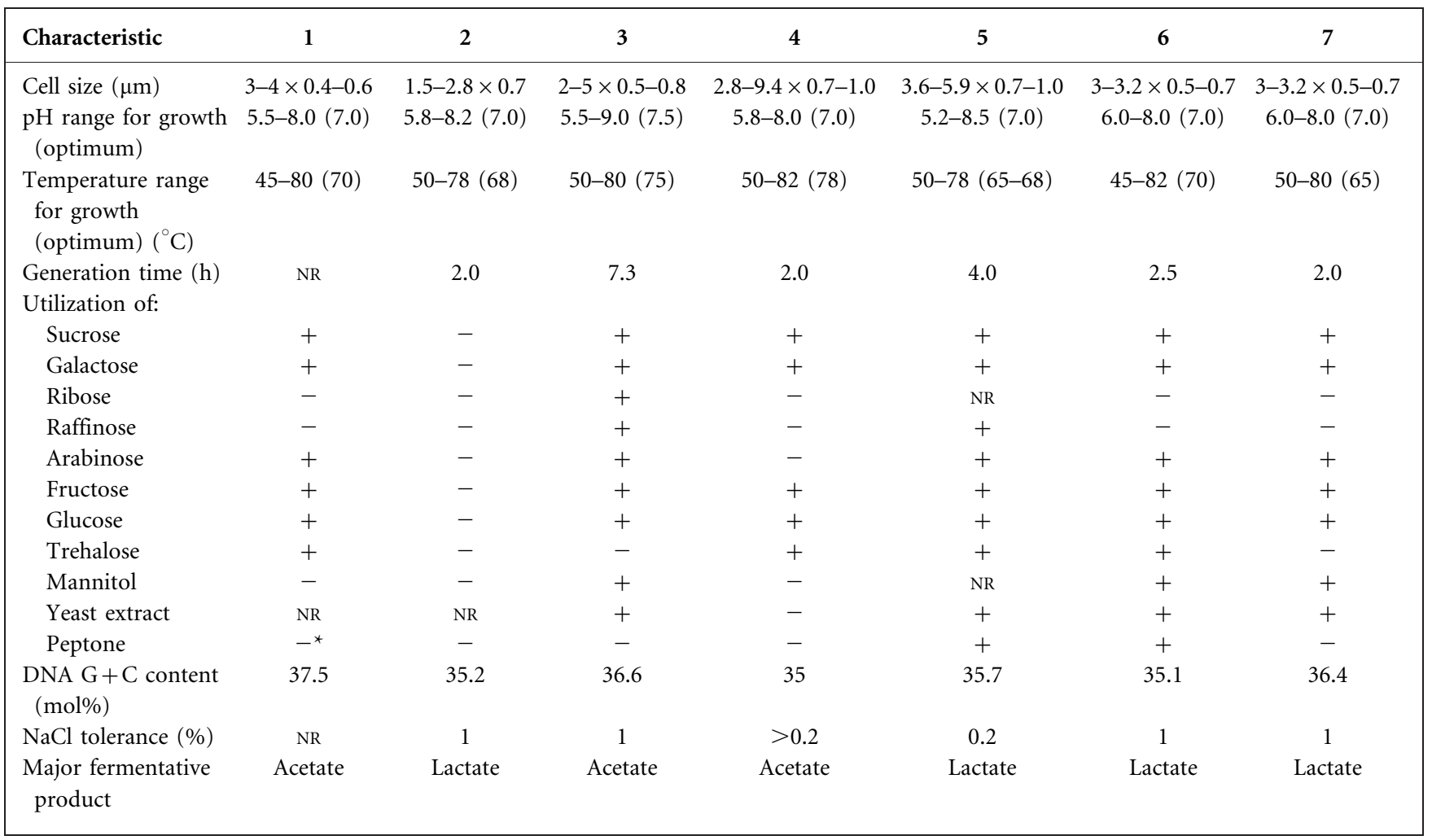

${ }^{\star}$ Data from this study. 
Chemo-organoheterotroph. Utilizes cellulose, CMcellulose, filter paper, starch, xylan, dextran, pectin, cellobiose, glucose, fructose, sucrose, xylose, galactose, maltose, lactose, arabinose, trehalose, mannitol, yeast extract and peptone. Does not grow with pyruvate, chitin, raffinose or ribose. Fermentation products are lactate and acetate. The $\mathrm{G}+\mathrm{C}$ content of the DNA of the type strain is $35.1 \mathrm{~mol} \%$.

The type strain, $2002^{\mathrm{T}}\left(=\mathrm{DSM} 18902^{\mathrm{T}}=\mathrm{VKM} \mathrm{B}-2412^{\mathrm{T}}\right)$, was isolated from a terrestrial neutral geothermal spring in Geyser Valley, Kamchatka. Strains 2902 and 2006 are reference strains.

\section{Description of Caldicellulosiruptor hydrothermalis sp. nov.}

Caldicellulosiruptor hydrothermalis (hy.dro.ther' ma.lis. N.L. masc. adj. hydrothermalis pertaining to hydrothermal vents).

Cells are short, straight rods $(3-3.2 \times 0.5-0.7 \mu \mathrm{m})$ with flagella. Cell wall is of Gram-positive type. Non-sporeforming. Strictly anaerobic. Temperature range for growth is $50-80{ }^{\circ} \mathrm{C}$, with optimum growth at $65{ }^{\circ} \mathrm{C}$; $\mathrm{pH}$ range for growth is 6.0-8.0, with optimum growth at $\mathrm{pH}$ 7.0. Chemo-organoheterotroph. Utilizes cellulose, CM-cellulose, filter paper, starch, xylan, dextran, pectin, cellobiose, glucose, fructose, sucrose, xylose, maltose, galactose, lactose, arabinose, mannitol and yeast extract. Does not grow with pyruvate, chitin, raffinose, trehalose, ribose or peptone. Main fermentation products are lactate and acetate. The $\mathrm{G}+\mathrm{C}$ content of the DNA of the type strain is $36.4 \mathrm{~mol} \%$.

The type strain, $108^{\mathrm{T}}\left(=\mathrm{DSM} 18901^{\mathrm{T}}=\mathrm{VKM} B-2411^{\mathrm{T}}\right)$, was isolated from a terrestrial neutral geothermal spring in the southern region of Kamchatka.

\section{Acknowledgements}

We are grateful to Professor E. Stackebrandt, Dr S. Spring and Professor J. Wiegel for kindly providing the type strains of reference Caldicellulosiruptor species. This study was supported by the Programs of the Russian Academy of Sciences 'Origin of Life and Biosphere Evolution' and 'Molecular and Cell Biology', and by the Russian Foundation of Basic Research, grant no. 05-04-48058, and by NATO grant ST.CLG.978868.

\section{References}

Bergquist, P. L., Saul, D. J., Gibbs, M. D., Morris, D. D., Te'o, V. S. J. \& Morgan, H. W. (1999). Molecular diversity of thermophilic cellulolytic and hemicellulolytic bacteria. FEMS Microbiol Ecol 28, 99-110.
Bonch-Osmolovskaya, E. A., Sokolova, T. G., Kostrikina, N. A. \& Zavarzin, G. A. (1990). Desulfurella acetivorans gen. nov. and sp. nov. - a new thermophilic sulfur-reducing eubacterium. Arch Microbiol 153, 151-155.

Bredholt, S., Sonne-Hansen, J., Nielsen, P., Mathrani, I. M. \& Ahring, K. (1999). Caldicellulosiruptor kristjanssonii, sp. nov., a cellulolytic, extremely thermophilic, anaerobic bacterium. Int J Syst Bacteriol 49, 991-996.

Garrity, G. M., Boone, D. R. \& Castenholz, R. W. (editors) (2001). Bergey's Manual of Systematic Bacteriology, vol. 1, 2nd edn. New York: Springer.

Huang, C.-Y., Patel, B. K., Mah, R. A. \& Baresi, L. (1998). Caldicellulosiruptor owensensis sp. nov., an anaerobic, extremely thermophilic, xylanolytic bacterium. Int J Syst Bacteriol 48, 91-97.

Jukes, T. H. \& Cantor, C. R. (1969). Evolution of protein molecules. In Mammalian Protein Metabolism, vol. 3, pp. 21-132. Edited by H. N. Munro. New York: Academic Press.

Miroshnichenko, M. L., Gongadze, G. A., Lysenko, A. M. \& BonchOsmolovskaya, E. A. (1994). Desulfurella multipotens sp. nov., a new sulfur-respiring thermophilic eubacterium from Raoul Island (Kermadec archipelago, New Zealand). Arch Microbiol 161, 88-93.

Mladenovska, Z., Mathrani, I. M. \& Ahring, B. K. (1995). Isolation and characterization of Caldicellulosiruptor lactoaceticus sp. nov., an extremely thermophilic, cellulolytic, anaerobic bacterium. Arch Microbiol 163, 223-230.

Onyenwoke, R. U., Lee, Y.-J., Dabrowski, S., Ahring, B. K. \& Wiegel, J. (2006). Reclassification of Thermoanaerobium acetigenum as Caldicellulosiruptor acetigenus comb. nov. and emendation of the genus description. Int J Syst Evol Microbiol 56, 1391-1395.

Pfennig, N. (1965). Anreicherungskulturen für rote und grüne Schwefelbakterien. Zentralbl Bakteriol I Abt IS (Suppl. V), 179-185.

Pfennig, N. \& Lippert, K. D. (1966). Über das Vitamin B12-Bedürfnis phototropher Schwefelbacterien. Arch Microbiol 55, 245-256.

Rainey, F. A., Donnison, A. M., Janssen, P. H., Saul, D., Rodrigo, A., Berquist, P. L., Daniel, R. M., Stackebrandt, E. \& Morgan, H. W. (1994). Description of Caldicellulosiruptor saccharolyticus gen. nov., sp. nov.: an obligately anaerobic, extremely thermophilic, cellulolytic bacterium. FEMS Microbiol Lett 120, 263-266.

Svetlichnii, V. A. \& Svetlichnaya, T. P. (1988). Dictyoglomus turgidus sp. nov., a new extreme thermophilic eubacterium isolated from hot springs in the Uzon volcano crater. Microbiology (English translation of Mikrobiologiia) 57, 435-441.

Svetlichnii, V. A., Svetlichnaya, T. P., Chernych, N. A. \& Zavarzin, G. A. (1990). Anaerocellum thermophilum gen. nov., an extreme thermophilic cellulolytic eubacterium isolated from hot springs in the valley of Geysers. Microbiology (English translation of Mikrobiologiia) 59, 871-879.

Van de Peer, Y. \& De Wachter, R. (1994). TREECON for Windows: a software package for the construction and drawing of evolutionary trees for the Microsoft Windows environment. Comput Appl Biosci 10, 569-570.

Wolin, E. A., Wolin, M. J. \& Wolfe, R. S. (1963). Formation of methane by bacterial extracts. J Biol Chem 238, 2882-2886. 